\title{
Trends, Abrupt Changes, and Periodicity of Streamflow in Qinghai Province, the Northeastern Tibetan Plateau, China
}

\author{
Bo Chang, 2,3**, Kangning He ${ }^{1,2,3 *}$, Runjie $\mathrm{Li}^{4}$, Hui Wang', 2,3, Jun Wen \\ ${ }^{1}$ College of Soil and Water Conservation, Beijing Forestry University, Key Laboratory of State Forestry Administration \\ on Soil and Water Conservation, Beijing, 100083, China \\ ${ }^{2}$ Beijing Forestry University, Beijing Engineering Research Center of Soil and Water Conservation, \\ Beijing 100083, China \\ ${ }^{3}$ Beijing Forestry University, Engineering Research Center of Forestry Ecological Engineering, \\ Ministry of Education, Beijing 100083, China \\ ${ }^{4}$ Institute of Water Resources and Hydropower of Qinghai Province, Xining 810001, China
}

\author{
Received: 17 March 2017 \\ Accepted: 23 July 2017
}

\begin{abstract}
The Qinghai-Tibet Plateau is a more sensitive area of climate change and fragile zone of ecological environment. Qinghai Province is an important component of the Qinghai-Tibet Plateau, and the study of streamflow in the province is of great significance for understanding the situation of water resources. Based on hydrological data of hydrological stations in Qinghai, the spatiotemporal variations of streamflow from 1956 to 2013 were analyzed by Mann-Kendall analysis and Morlet wavelet analysis. The results indicated that the annual streamflow of the Yangtze River basin, Qaidam basin, Qinghai Lake basin, and Lantsang River basin showed significantly increasing trends during 1956-2013, while the Yellow River basin showed no significant trends or downward trends. Changes in precipitation, glacier melt, and snowmelt caused by climate warming might be a major driver of changes of streamflow in the source regions of the Yangtze River and Lantsang River basins. The trend variations of flow in the Yellow River basin may be affected by precipitation, evaporation caused by increased temperature, and anthropogenic impacts. The abrupt changes of streamflow at Tuotuohe, Delingha, and Nachitai stations were mainly in the early 2000s, while the abrupt changes of streamflow in Zhimenda station, stations in the Yellow River basin, Qinghai Lake basin, and Lantsang River basin appeared primarily in the early 1960s and the early 2000s. Most of the streamflow in Qinghai Province was abundant after about 2007, and the dominant periods with low frequency fluctuation (about 12 years) and inter-decadal (about 44 years) oscillations in Zhimenda and Tangnaihai stations and low frequency fluctuation (about five years) in other stations.
\end{abstract}

Keywords: streamflow variation, Mann-Kendall, wavelet transforms, Yangtze River basin, Yellow River basin

*e-mail: hkn@bjfu.edu.cn

**e-mail: changbo3979@163.com 


\section{Introduction}

Against the background of global warming, the spacetime variation of hydrological factors has been the focus of researchers' attention [1-2]. Qinghai Province is the protective ecological barrier of the northeastern part of the Qinghai-Tibetan Plateau, where surface water faces various problems due to the complex geographical location, permafrost degradation, and climate change [3]. In addition, the rapid development of agriculture and industry, and the rapid growth of population in Qinghai Province in recent years not only has exacerbated the situation of water resource shortages, but also seriously restricted the development of the regional economy [4-5]. Therefore, a study on the characteristics of variation in streamflow in Qinghai Province - especially streamflow in the Three-River Source Region (TRSR: the origin of the Yangtze, Yellow, and Lantsang rivers, which has a significant effect on runoff of the major rivers in China) - plays a very important role in rational development and the utilization of water resources, making water conservancy planning decisions and improving the ecological situation of the environment.

There are many studies on runoff in the source region of the Yangtze River Basin and the Yellow River Basin. Bian, H. Q. and $\mathrm{Wu}, \mathrm{S} . \mathrm{S}$. Bian and $\mathrm{Wu}$ [6-7] studied the effects of climate change and glacier retreat on streamflow in the source region of the Yangtze. Qian et al. [8] used the Morlet wavelet method to reveal the periodical characteristics of base flow in the source region of the Yangtze. Zhang and $\mathrm{Hu}$ [9-10] studied runoff variation and climate linkages in the TRSR and the source region of the Yellow River, respectively. However, most of these studies focus on the impact of climate change on water resources, and less systematic analysis of the formation process of runoff and its temporal and spatial evolution rules and causes, and few studies have been done on the streamflow within Qinghai Province as a whole, so that there is great need to conduct a comprehensive study on Qinghai streamflow.

Various methods have been used to analyze the trend, abrupt change, and periodicity of streamflow. In recent years, the statistical method of Mann-Kendall and wavelet analysis has developed rapidly, with the MannKendall statistical test being widely used in different regions to identify whether monotonic trends and abrupt change exists in streamflow [11-13], and wavelet analysis has been widely used in different regions to identify the periodicity of streamflow [14-15].

To fill the knowledge gap as identified above, in this study we used the Mann-Kendall trend test and changepoint analysis to analyze the trends and abrupt changes of streamflow in the Yangtze River, Yellow River, Lantsang River, Qaidam, and Qinghai Lake basins of the province to reveal the spatial and temporal evolution of the hydrological cycle. Meanwhile, wavelet analysis was used to understand the periodicity and the change of abundance and drought of streamflow in each station to systematically research dynamic changes of streamflow in Qinghai Province.

\section{Materials and Methods}

\author{
Study Area
}

Qinghai Province is located in northeastern Qinghai Tibet Plateau $\left(31^{\circ} 09^{\prime} \mathrm{N}-39^{\circ} 19^{\prime} \mathrm{N}, \quad 89^{\circ} 35^{\prime} \mathrm{E}-103^{\circ} 04^{\prime} \mathrm{E}\right.$; Fig. 1). The total area is more than $71.75 \times 10^{4} \mathrm{~km}^{2}$, which includes the Qinghai-Tibet Plateau and Loess Plateau [16]. The average altitude of the province is $4,000 \mathrm{~m}$ above sea level. This region belongs to plateau continental climate with characteristics of low temperature, large diurnal difference of temperature, less concentrated rainfall, long periods of sunshine, and strong solar radiation [17]. Annual precipitation is $273.7-467.8 \mathrm{~mm}$, with about $75 \%$ distributed between July and September, the rainy season. The annual mean temperature is $0.0-3.4^{\circ} \mathrm{C}$. The annual duration of sunshine is about $2,700 \mathrm{~h}$ and total annual radiation reaches 690.8-753.6 $\mathrm{kJ} / \mathrm{cm}^{2}$. The Yangtze, Yellow, Lantsang, Heihe and other famous rivers originate in Qinghai.

\section{Data}

The Tuotuohe gauge station at the head region of the Yangtze River Station and Zhimenda gauge station at the Tongtianhe River, a tributary of the upstream Yangtze, were selected to analyze the variation of streamflow in the Yangtze basin.

The Huangheyan gauge station at the headwater region of the Yellow River, the Tangnaihai gauge station on the main stream, and Minhe gauge station on the Huangshui River (a tributary of the Yellow River) were selected to

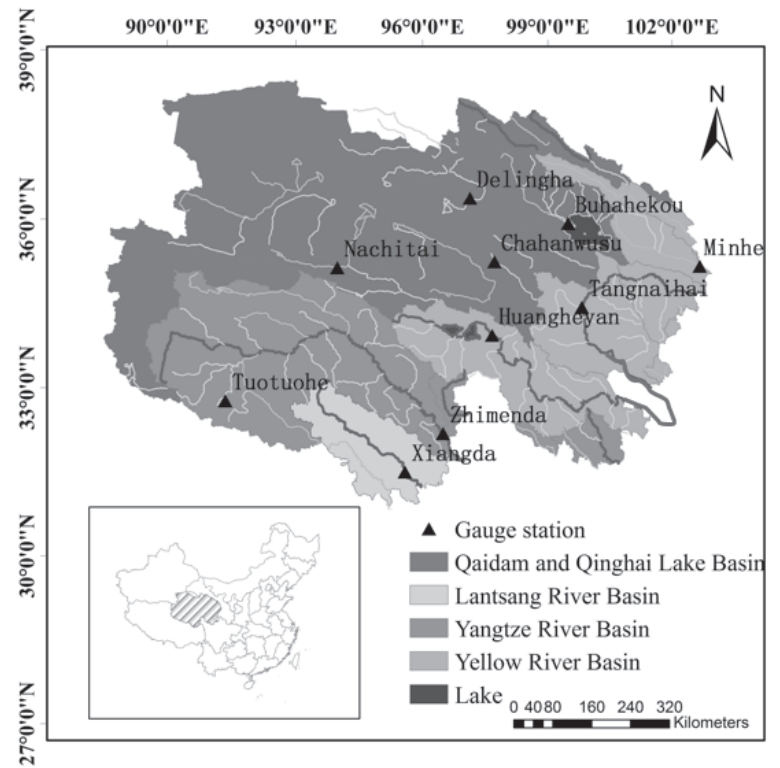

Fig. 1. Location of the study area. 
Table 1. Basic information of selected gauge stations.

\begin{tabular}{|c|c|c|c|c|c|}
\hline \multirow{2}{*}{ Basin } & Station name & $\begin{array}{c}\text { Latitude and } \\
\text { longitude }\end{array}$ & $\begin{array}{c}\text { Drainage area } \\
\left(\mathrm{km}^{2}\right)\end{array}$ & Time interval & Location description \\
\hline \multirow{3}{*}{ Yangtze River } & Tuotuohe & $33.2 \mathrm{~N}, 92.4 \mathrm{E}$ & 15,924 & $1956-2013$ & Headwater area \\
\cline { 2 - 6 } & Zhimenda & $33.0 \mathrm{~N}, 97.2 \mathrm{E}$ & 137,704 & $1956-2013$ & Tongtianhe control gate \\
\hline \multirow{3}{*}{ Yellow River } & Huangheyan & $34.9 \mathrm{~N}, 98.1 \mathrm{E}$ & 20,930 & $1956-2013$ & Headwater area \\
\cline { 2 - 6 } & Tangnaihai & $35.5 \mathrm{~N}, 100.2 \mathrm{E}$ & 121,972 & $1956-2013$ & Main stream control gate \\
\cline { 2 - 6 } & Minhe & $36.3 \mathrm{~N}, 102.5 \mathrm{E}$ & 15,342 & $1956-2013$ & Huangshui control gate \\
\hline \multirow{3}{*}{\begin{tabular}{c} 
Baidam \\
\cline { 2 - 6 }
\end{tabular}} & Delingha & $37.4 \mathrm{~N}, 97.4 \mathrm{E}$ & 7,281 & $1956-2013$ & Bayin River control gate \\
\cline { 2 - 6 } & Nachitai & $35.9 \mathrm{~N}, 94.5 \mathrm{E}$ & 5,973 & $1956-2013$ & Naijin River control gate \\
\hline Qinghai Lake & Buhahekou & $37.1 \mathrm{~N}, 99.7 \mathrm{E}$ & 14,337 & $1956-2013$ & Buhah River control gate \\
\hline Lantsang River & Xiangda & $32.3 \mathrm{~N}, 96.4 \mathrm{E}$ & 17,909 & $1956-2013$ & Zhaqu River control station \\
\hline
\end{tabular}

analyze the variation of streamflow in the Yellow River basin.

There are great differences in hydrological condition between southern and northern Qaidam Basin, resulting in different streamflows. The Delingha gauge station on the Bayin River in the northern region of Qaidam basin, the Nachitai gauge station on Naijin River in the southwestern region of the Qaidam basin, and the Chahanwusu gauge station in the southeastern region of Qaidam were selected to analyze the variations in streamflow in the Qaidam basin.

The main rivers in Qinghai Lake basin are the Buha, Shaliu, and Haergai rivers, the largest of which is the Buha. Buhahekou guage station was selected to analyze the variations of streamflow in the Qinghai basin.

Xiangda guage station was selected to analyze the variations of streamflow in the Lantsang River basin. All the basic information of the gauge stations are summarized in Table 1.

\section{Methods}

In this study the Mann-Kendall trend test and change-point analysis are used to investigate the trends, and abrupt changes of streamflow and wavelet analysis are used to understand the periodicity of streamflow in Qinghai.

\section{Mann-Kendall Trend Test}

The Mann-Kendall trend test is the rank-based nonparametric test for assessing the significance of a trend, and has been widely used in hydrological trend detection studies [18-19]. The null hypothesis $\mathrm{H}_{0}$ is that a sample of data $\left(x_{i}, i=1,2 \ldots n\right)$ is the nonexistence of a monotonic trend in a variable over time. The alternative hypothesis $\mathrm{H}_{1}$ is that a monotonic trend exists in $\mathrm{x}$ [20]. The MK test statistic (S) is calculated as follows:

$$
\begin{gathered}
S=\sum_{i=1}^{n=1} \sum_{j=i+1}^{n} \operatorname{sgn}\left(x_{j}-x_{i}\right) \\
\operatorname{sgn}(x)=\left\{\begin{array}{lll}
1, & \text { if } & x_{j}-x_{i}>0 \\
0, & \text { if } & x_{j}-x_{i}=0 \\
-1, & \text { if } & x_{j}-x_{i}<0
\end{array}\right.
\end{gathered}
$$

...where $x_{i}$ and $x_{j}$ are the date values of $x$ in years $i$ and $j$, and $n$ indicates the length of the date values. Mann (1945) and Kendall (1975) observed that when $n>10$, the statistic $\mathrm{S}$ is approximately normally distributed with the mean, and the variance is given by:

$$
\operatorname{Var}(S)=\frac{n(n-1)(2 n+5)}{18}
$$

Based on $\mathrm{S}$ and Var, the standardized MK statistics Z is computed by:

$$
Z=\left\{\begin{array}{lll}
\frac{S-1}{\sqrt{\operatorname{Var}(S)},} & \text { if } & S>0 \\
0, & \text { if } & S=0 \\
\frac{S+1}{\sqrt{\operatorname{Var}(S)},} & \text { if } & S<0
\end{array}\right.
$$

The standardized MK statistic Z follows the standard normal distribution with a mean of zero and variance of one. At a $5 \%$ significance level, the null hypothesis of no trend is rejected if $|Z|>1.96$ [21]. A positive value of $Z$ denotes an increasing trend, and the opposite corresponds to a decreasing trend [22-23]. 


\section{Mann-Kendall Change-Point Analysis}

Under the null hypothesis (no abrupt change point), the normally distributed statistic $\mathrm{S}_{\mathrm{k}}$ can be calculated by the following formula:

$$
\begin{gathered}
S_{k}=\sum_{i=1}^{k} \sum_{j=1}^{i-1} a_{i j} \quad(k=2,3,4 \cdots, n) \\
a i j=\left\{\begin{array}{lll}
1 & x_{i}>x_{j} & 1<j<i . \\
0 & x_{i}<x_{j}
\end{array}\right.
\end{gathered}
$$

Mean and variance of the normally distributed statistic $\mathrm{S}_{\mathrm{k}}$ can be given by the following formulas:

$$
\begin{gathered}
E\left(S_{k}\right)=\frac{k(k-1)}{4} \\
\operatorname{Var}=\frac{k(k-1)(2 k+5)}{72}
\end{gathered}
$$

The normalized variable statistic $\mathrm{UF}_{\mathrm{k}}$ is estimated as follows:

$$
\mathrm{UF}_{\mathrm{k}}=\frac{S_{k}-E\left(S_{k}\right)}{\sqrt{\operatorname{Var}\left(S_{k}\right)}} \quad(k=1,2,3, \cdots n)
$$

The normalized variable statistic $\mathrm{UF}_{\mathrm{k}}$ is the forward sequence, and the backward sequence $\mathrm{UB}_{\mathrm{k}}$ is calculated using the same equation but with a reversed series of data. The values of $U_{k}\left(U_{k}\right)$ constitute a forward sequence curve UF (UB). For the given $\alpha$ significance level and $\mathrm{U} \alpha$ (the critical value of the standard normal distribution), if $\mathrm{UF}_{\mathrm{k}}>\mathrm{U} \alpha$, it means the forward sequence curve (UF) has a trend $\alpha$ significance level [24]. The detection of an increasing $\left(\mathrm{UF}_{\mathrm{k}}>0\right)$ or a decreasing $\left(\mathrm{UF}_{\mathrm{k}}<0\right)$ trend is indicated. The intersection of the UF and UB curves of the test statistic appears in the confidence interval and indicates an abrupt change point [25]. All the trend and change point analyses were carried out using MATLAB R2014a software.

\section{Wavelet Analysis}

Based on the results of time-scale distribution, wavelet transform makes it easy to analyze the periodicity of streamflow series [26]. For time series $f(t) \in L^{2}(R)$, the continuous wavelet transform (CWT) is defined as the sum over all time of the real signal $f(t)$; multiplied by the scaled, the definition of CWT is:

$$
W_{f}(\mathrm{a}, \mathrm{b})=|a|^{-1 / 2} \int_{-\infty}^{\infty} f(\mathrm{t}) \psi\left(\frac{t-b}{a}\right) d t
$$

...where the wavelet coefficients $W_{f}(\mathrm{a}, \mathrm{b})$ are the result of the CWT of signal $f(t)$, and $\mathrm{a}$ and $\mathrm{b}$ are scale and translation, respectively.

In this study, the complex Morlet wavelet was adopted to analyze the periodic characteristics of natural streamflow in relation to time. The complex Morlet wavelet is a single-frequency complex sinusoidal function tapered with a Gaussian window, and is expressed as:

$$
\psi(t)=e^{i c t} e^{-t^{2} / 2}
$$

...where $\mathrm{c}$ is a constant and i represents an imaginary part. The main period of on-time series is obtained by wavelet variance, which is expressed as follows:

$$
\operatorname{Var}(a)=\sum\left(W_{f}\right)^{2}(a, b)
$$

Since wavelet variance denotes the distribution of wavelet energy by scale (period), the domain predominant

Table 2. Summary of hydrological results at the 10 stations.

\begin{tabular}{|c|c|c|c|c|}
\hline Station & Slope of regression & Z statistic & Intersected time & Main periodicity \\
\hline Tuotuohe & 0.67 & 2.87 & 2001,2003 & $29,19,8,5$ \\
\hline Zhimenda & 0.46 & 2.02 & 1967,2006 & $44,29,20,12$ \\
\hline Huangheyan & 0.03 & 0.02 & $1961,1991,2009$ & $56,13,6$ \\
\hline Tangnaihai & -0.16 & -0.46 & 1989 & $56,44,25,12$ \\
\hline Minhe & -1.29 & -1.33 & 1964,1989 & $43,12,5$ \\
\hline Delingha & 0.28 & 2.28 & 2001 & $44,25,12,9,5$ \\
\hline Nachitai & 0.58 & 5.31 & 2001 & $44,8,5$ \\
\hline Chahanwusu & 0.27 & 1.87 & 1967 & $56,25,12,5$ \\
\hline Buhahekou & 0.22 & 0.84 & $1963-68,2007$ & $56,48,34,18,12,5$ \\
\hline Xiangda & 0.58 & 1.57 & $1962-97$ & $57,43,29,21,13,5$ \\
\hline
\end{tabular}



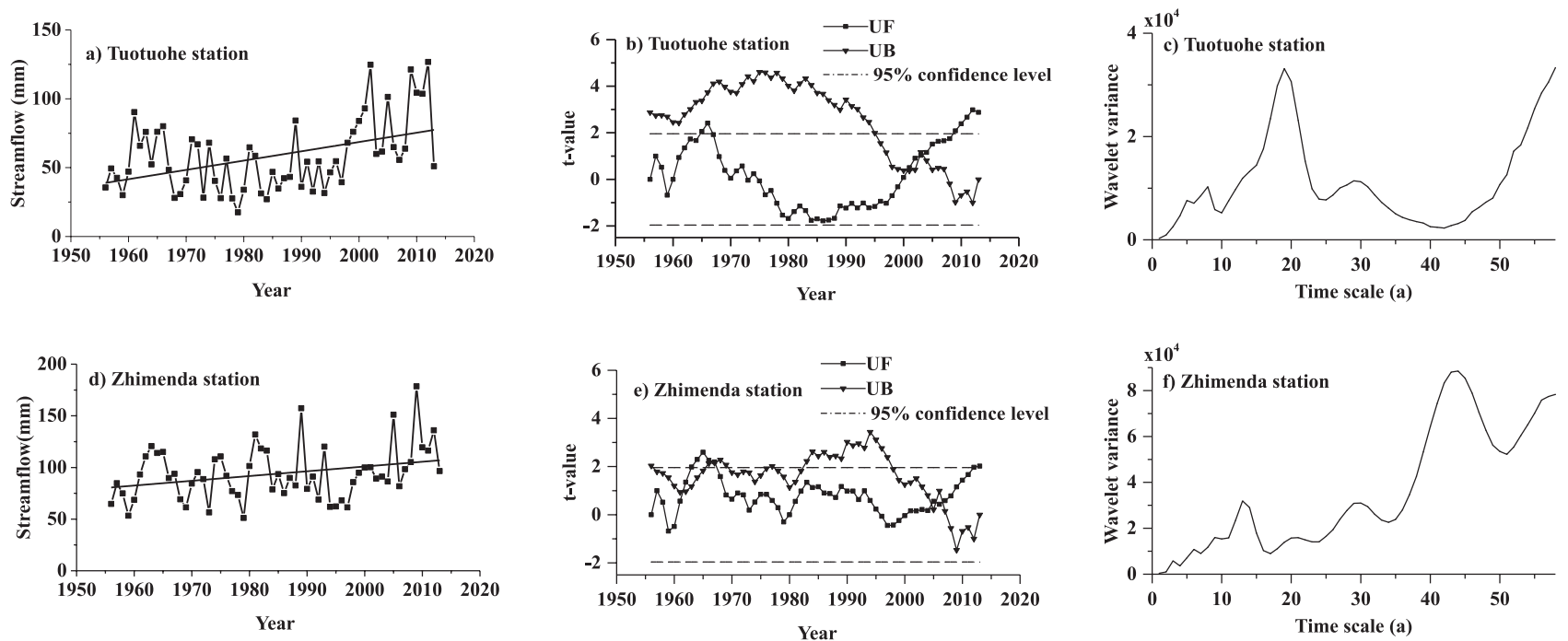

Fig. 2. Trend, abrupt change, and periodicity of streamflow in the Yangtze River Basin.

periods of one time series can be obtained from its extreme values. All the wavelet transform processes were carried out using MATLAB R2014a software.

\section{Results}

\section{Yangtze River Basin}

\section{Tuotuohe Station}

Linear regression exhibits annual streamflow at Tuotuohe Station with an upward trend during 19562013 (Table 2 and Fig. 2a). Analyzing further the virtue of the MK test, the Z statistic of streamflow is 2.87 $(|Z|>1.96)$, which showed that the annual streamflow is not only on an upward trend, but also the trend is significant at $95 \%$ confidence level. The intersection points of UF and UB curves indicate two abrupt changes of streamflow at Tuotuohe - in 2001 and 2003 (Table 2 and Fig. 2b).

By using Morlet wavelet transformation, streamflow periodicity at Tuotuohe within a 58-year scale is detected. From the real part wavelet coefficient, there were five periodical patterns within the 58-year scale, namely $>50$ years, 25-35, 15-23, 6-9, and about 5 years. For the $>50$ years scale, there are circa two-cycle oscillations. The periods of 1963-79 and 2003-13 are abundant-water periods (wave coefficients $>0$ ), while 1956-62 and 1980-2002 are low-water periods (wave coefficients $<0$ ). For the 6-9- and 5-year scales, there are more cycle oscillations, and the oscillation frequencies are more complicated. The main period can be obtained from the peak values of wavelet variance. Within a 58-year scale, there are circa 5, 8, 19, and 29 periods, and the 19-year period is the strongest (Table 2 and Fig. 2c).

\section{Zhimenda Station}

Linear regression exhibits annual streamflow at Zhimenda Station with an upward trend during 1956-2013 (Table 2 and Fig. 2d). The increasing rate of streamflow at Zhimenda was slower than that at Tuotuohe. The Z statistic of streamflow is $2.02(|Z|>1.96)$, and showed a significant upward trend at the $95 \%$ confidence level. The intersection points of the curves at Zhimenda appeared in 1967 and 2006 (Table 2 and Fig. 2e).

The streamflow series at Zhimenda has four periodical patterns: namely 38-47, 26-32, 10-15, and <10-year periodical character within the 58-year scale. For the 3847 scale, there are three-cycle oscillations. The periods of 1956-63, 1980-92, and after 2007 are the abundant water periods, while 1964-79 and 1993-2006 are lowwater periods. Within a 58 -year scale, the periodicity of the streamflow is located into circa 12-, 20-, 29-, and 44year periods, and the 44-year period is the most obvious (Table 2 and Fig. 2f).

\section{Yellow River Basin \\ Huangheyan Station}

Different from the Yangtze River Basin, the streamflow series at Huangheyan Station of the Yellow River presents no significant trend during 1956-2013, and the slope of the linear regression was 0.03 (Table 2 and Fig. 3a). The MK test shows that the $\mathrm{Z}$ statistic of streamflow was $0.02(|Z|<1.96)$. The intersection points of UF and UB curves occurred at circa 1961, 1991, and 2009 for the streamflow at Huangheyan (Table 2 and Fig. 3b).

The streamflow at Huangheyan presents the periods of 50-58, 9-15, and $<8$ years. For the 50-58-year scale, there are two-cycle oscillations. The periods of 1968-86 and after 2007 are the abundant water periods, while 1956-67 and 1987-2006 are the low-water periods. The 


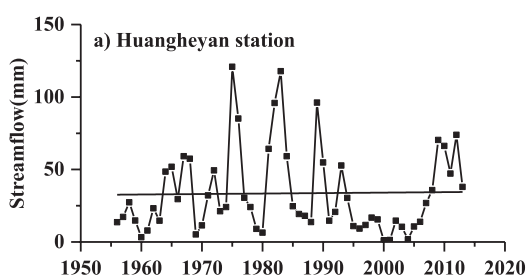

Year
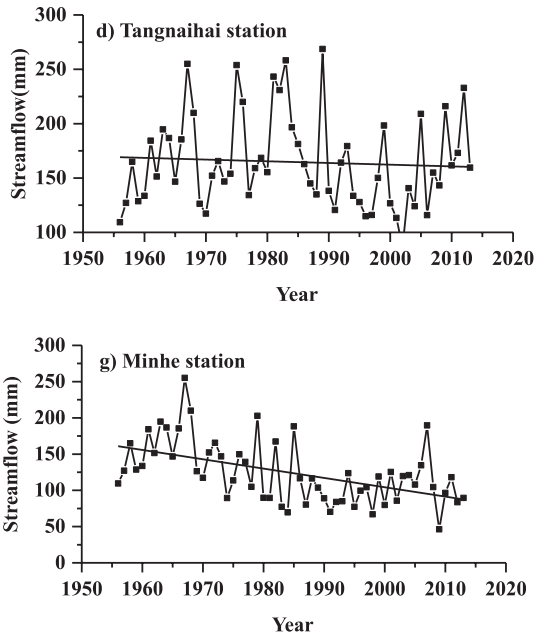

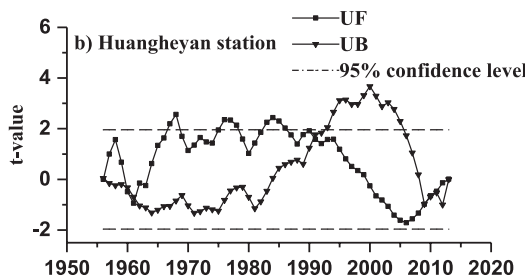

Year

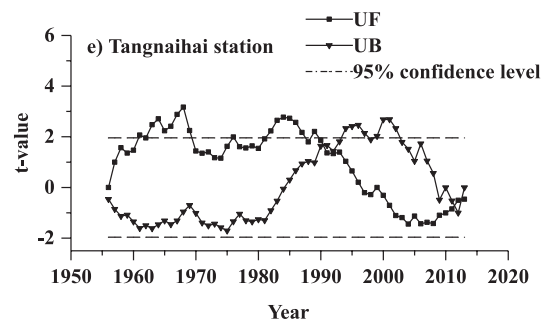

$\longrightarrow$ UF

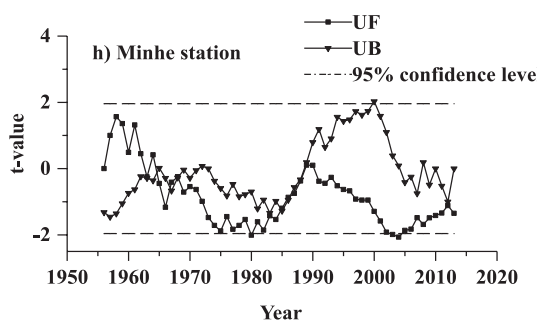

Year
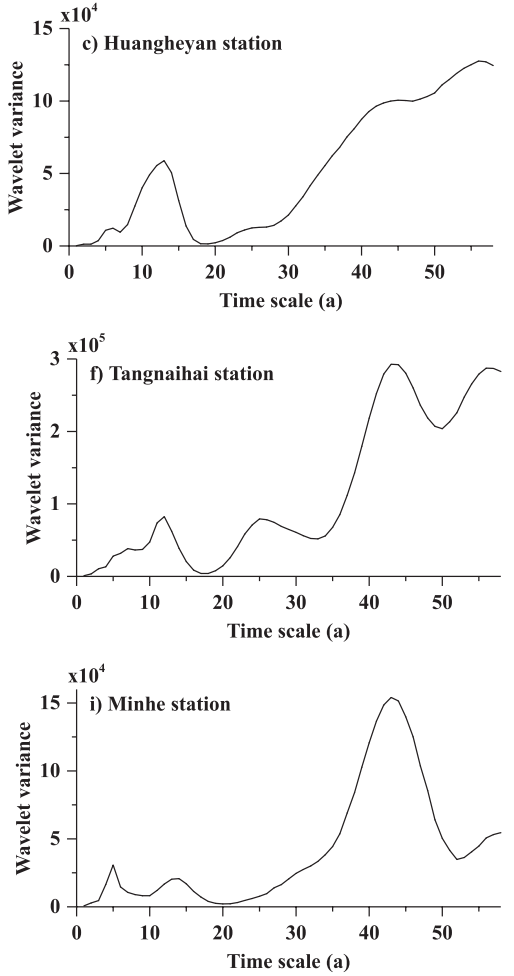

Fig. 3. Trend, abrupt change, and periodicity of streamflow in the Yellow River Basin.

main periodicity of 6,13 , and 56 years for the streamflow was obtained from wavelet variance, and the 56-year period is the strongest with the 58-year scale (Table 2 and Fig. 3c).

\section{Tangnaihai Station}

The streamflow series presents a downward trend at Tangnaihai Station during 1956-2013. The result of the MK trend test show that the $\mathrm{Z}$ statistic of streamflow was $-0.46(|Z|<1.96)$, which showed that the downward trend was not significant at $95 \%$ confidence level (Table 2 and Fig. 3d). The intersection points of UF and UB curves at Tangnaihai appeared in 1989, and the two curves were between the two confidence lines, so the abrupt change took place at 1989 (Table 2 and Fig. 3e).

The periods of streamflow at Tangnaihai were $50-58,40-47,20-32$, and about 12 years. For the 5058 scale, there are two-cycle oscillations. Streamflow was plentiful during 1956-65, 1978-92, and from 2006 to a certain year in the future, and have been in low streamflow during 1966-77 and 1993-2005. The main periodicity of $12,25,44$, and 56 years is obtained, and the 44-year period was the most obvious in Tangnaihai (Table 2 and Fig. 3f). Considering the control areas of the two stations (more than $100,000 \mathrm{~km}^{2}$ ), the dominant period with low frequency fluctuation is about 12 years and with inter-decadal oscillations is about 44 years, which is the same as the characteristics at Zhimenda Station.

\section{Minhe Station}

The streamflow series at Minhe Station presents a downward trend during 1956-2013, when the slope of the linear regression was -1.29 (Table 2 and Fig. 3g). But the trend was not significant at the $95 \%$ confidence level $(Z=-1.33)$. The result of MK test for abrupt change showed that the intersection points of UF and UB curves appeared in 1964 and 1989 (Table 2 and Fig. 3h).

The streamflow series at Minhe presents periods of 40-49, 10-15, and 4-6 years. Based on the calculation of wavelet variance, quantitative periodicity is located into circa 5, 12, and 43 years, and the 43 -year cycle is the most obvious (Table 2 and Fig. 3i). Moreover, through contour maps of wavelet coefficients there are threecycle oscillations in the 40-49 scale. The stream was in low-flow conditions during 1965-80 and 1994-2007, and abundant during 1956-64, 1981-93, and after 2007.

\section{Qaidam Basin}

Annual streamflow at Delingha, Nachitai, and Chahanwusu stations showed a significantly increasing trend based on the MK test (Table 2). It can be seen from Figure 4 that the intersection point appeared in 2001 at the Delingha and Nachitai. Although the intersection point was not between the two confidence lines at Nachitai, there was a significant sudden streamflow increase to a certain extent in 2001.

The quantitative periodicity Delingha station is located in circa $5,9,12,25$, and 44 years, and the 

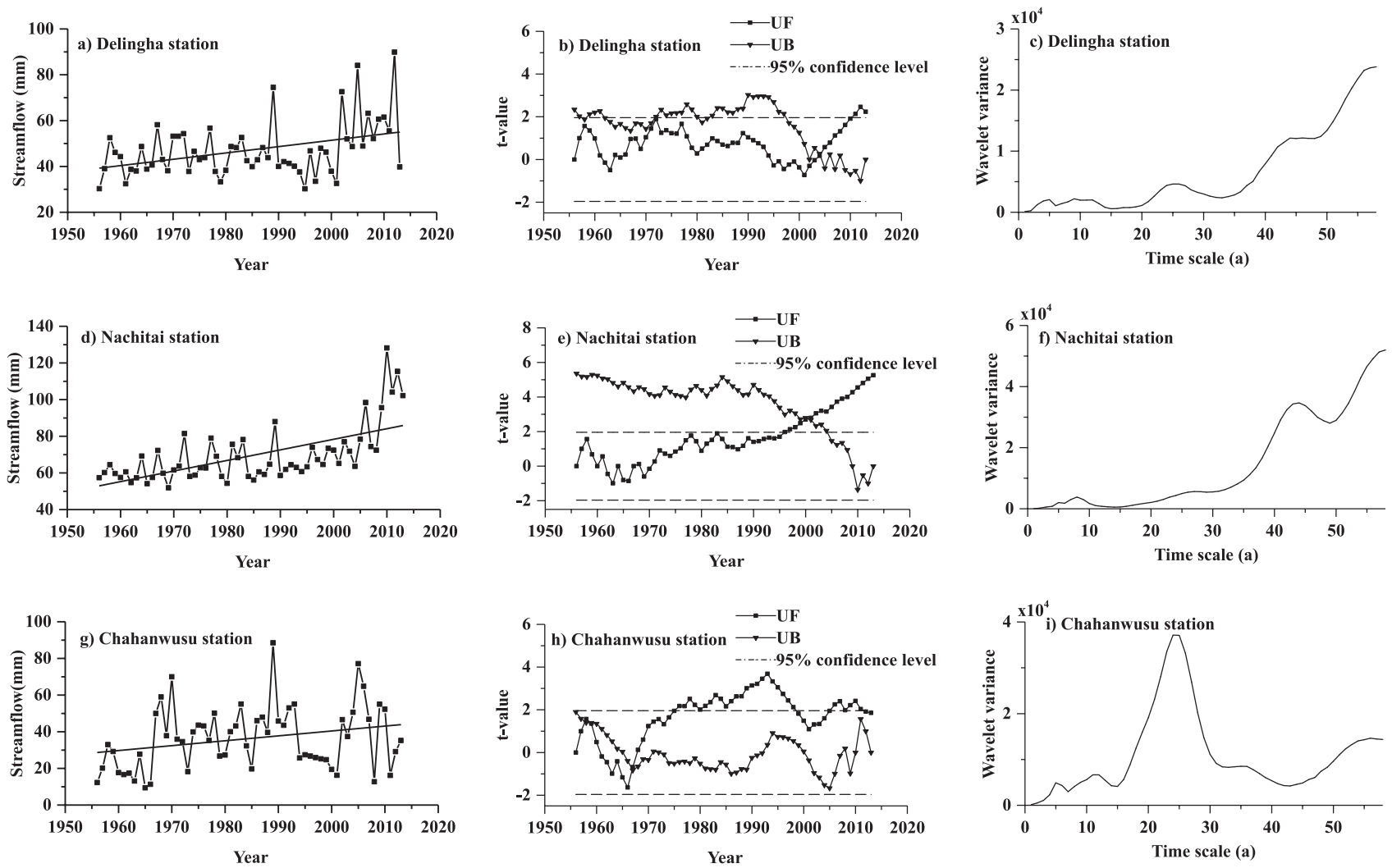

Fig. 4. Trend, abrupt change, and periodicity of streamflow in the Qaidam Basin.

44-year cycle is the most obvious (Table 2 and Fig. 4c). The streamflow series at Nachitai present periods with $>55,40-45,8-9$, and 4-6 years. Based on the calculation of wavelet variance, quantitative periodicity is located into circa 5, 8, and 44 years, and the 44-year cycle is the most obvious (Table 2 and Fig. 4f). Streamflow was in low streamflow condition during 1956-66 and 1983-2001, and abundant during 1967-82 and after 2004. The quantitative periodicity at Chahanwusu Station is located in circa 5, 12,25 , and 56 years, and the 25-year cycle is the most obvious (Table 2 and Fig. 4i).

Considering the control areas of the three stations (less than $10,000 \mathrm{~km}^{2}$ ), the dominant period with low frequency fluctuation is about 5 years at Chahanwusu Station, which has the same characteristics as Delingha and Nachitai.

\section{Qinghai Lake Basin}

The streamflow series presents an increasing trend at Buhahekou Station during 1956-2013 (Table 2 and Fig. 5a). There are several intersection points from 1963-68, with more performance for a periodic fluctuation and another intersection point appearing in 2007 (Table 2 and Fig. 5b).

The streamflow series at Buhahekou presents periods with >50, 23-40, 10-18, and 4-6 years. Based on the calculation of wavelet variance, quantitative periodicity is located in circa $5,12,18,34,48$, and 56 years, and the 34 year cycle is the most obvious (Table 2 and Fig. $5 \mathrm{c}$ ). There are three-cycle oscillations in the 34 scale. The periods of 1962-73, 1985-96, and after 2007 are the abundant-water periods, while 1956-61 and 1997-2006 are the low-water periods.
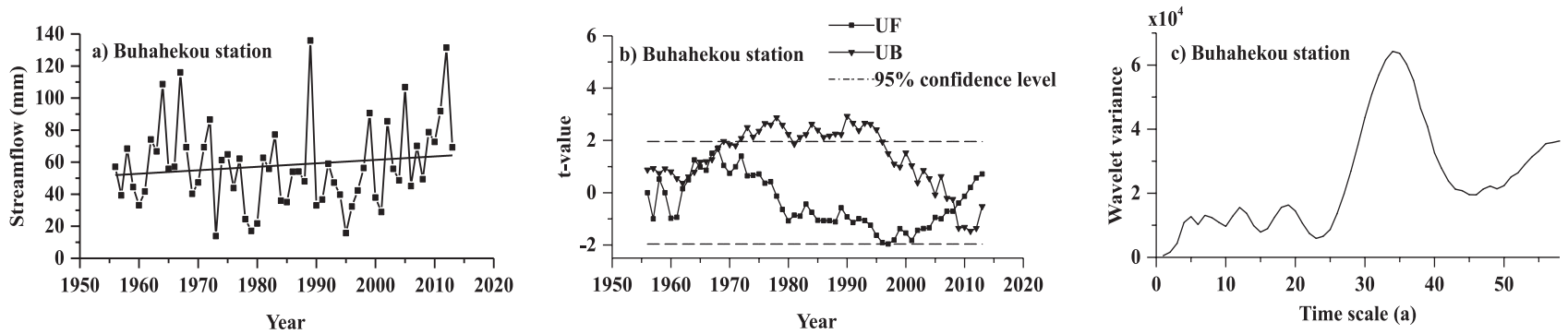

Fig. 5. Trend, abrupt change, and periodicity of streamflow in the Qinghai Lake Basin. 

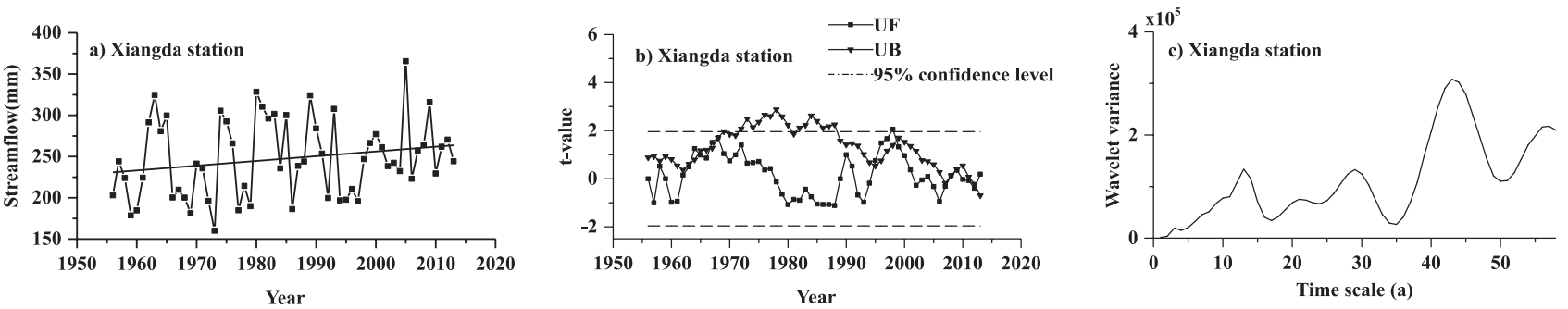

Fig. 6. Trend, abrupt change, and periodicity of streamflow in the Lantsang River Basin.

\section{Lantsang River Basin}

The streamflow series presents the increasing trend at Xiangda Station during 1956-2013 (Fig. 6a). There have several intersection points from 1962-97, and more performance for periodic fluctuation (Table 2 and Fig. 6b).

Based on the calculation of wavelet variance, quantitative periodicity is located into circa $5,13,21$, 29,43 , and 57 years. The most obvious periodicity is 43 years for the streamflow series. Through contour maps of wavelet coefficients, there are three-cycle oscillations in the 43 scale. The periods of 1956-65, 1979-92, and after 2007 are the abundant-water periods, while 196678 and 1993-2006 are the low-water periods (Table 2 and Fig. 6c).

Considering the control areas of the five stations $\left(14,000-21,000 \mathrm{~km}^{2}\right)$, the dominant periods with low frequency fluctuation are about 5 years at Xiangda Station, which is the same as the characteristics at Tuotuohe, Huangheyan, Minhe, and Buhahekou stations.

\section{Discussion}

\section{Trend}

In the period 1956 to 2013, streamflow shows increasing trends in the Yangtze River, Qaidam, Qinghai Lake, and Lantsang River basins. On the contrary, the streamflow trend in the Yellow River Basin is no significant trend in Huangheyan Station (streamflow increased by $0.03 \mathrm{~mm} / \mathrm{a}$ ) and a downward trend in Tangnaihai (streamflow decreased by $0.16 \mathrm{~mm} / \mathrm{a}$ ) and Minhe Station (streamflow decreased by $1.29 \mathrm{~mm} / \mathrm{a}$ ). This was indicated in the sense that Minhe in the Yellow River Basin is at the highest risk of water scarcity among the investigated river basins, with Tangnaihai less severe than Minhe. In contrast, the other four basins in Qinghai Province show a general increase in streamflow over the study period and might not, therefore, be threatened by water scarcity in the near future. Similar results show that there is a potential water resource crisis in the Yellow River basin because continued low levels from the 1990s could be seen from the study of He B [27]. The eastern agricultural area is less than 5\% of the total area of Qinghai Province, which is inhabited by $75 \%$ of the population; the western animal husbandry area accounts for more than $95 \%$ of the total area, but is only $25 \%$ of the total population. Moreover, in recent decades - especially after reform and opening up in China - reclamation, construction of reservoirs, afforestation, and other human activities have intensified. Hence the trend variations of flow in the Yellow River Basin may be affected by anthropogenic impacts such as reservoirs [28], water consumption for irrigation, and increasing forest cover [29-30]. Similar analysis can also be seen in previous studies [28].

Minhe is the last gauge station in the Huangshui River, a tributary of the Yellow. According to the corresponding historical precipitation and temperature records of Minhe, annual precipitation is seeing a downward trend, while the annual temperature saw an upward trend during 1956-2013 (Fig. 7). The significant correlation $(\mathrm{R}=0.61$, $P<0.01)$ between streamflow and annual precipitation of Minhe, which exhibits precipitation, is the key variable influencing streamflow. A negative correlation $(P>0.05)$ between streamflow and annual temperature of Minhe was found in this research [26]. An increase of temperature leads to the increase of potential and actual evaporation,
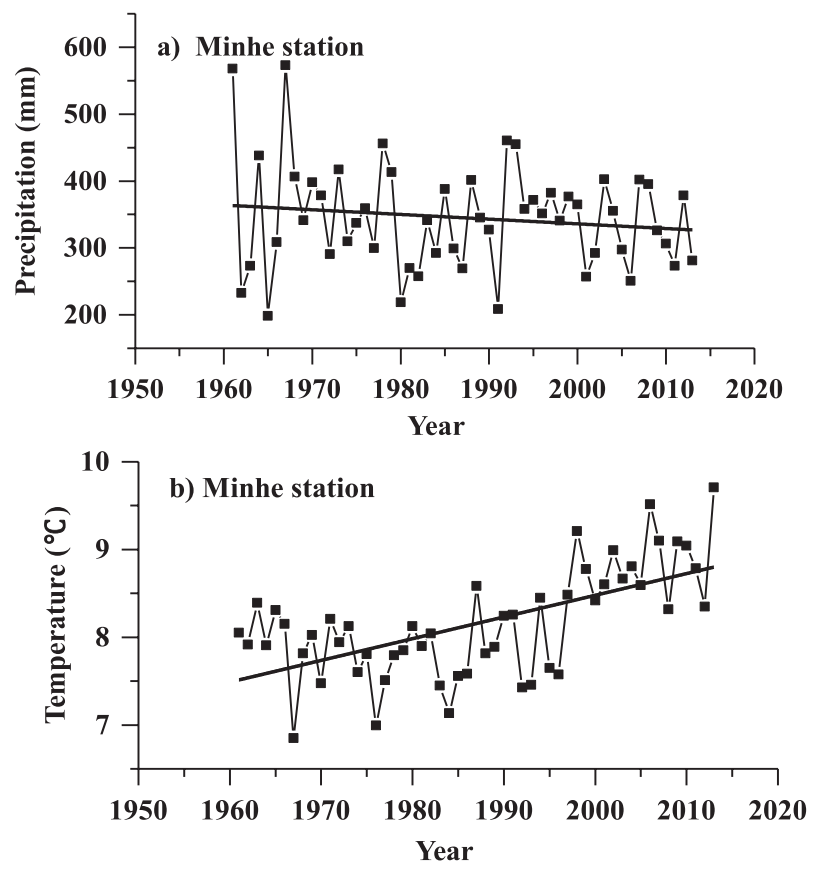

Fig. 7. Changes of streamflow, precipitation, and temperature at Minhe Station in the Yangtze River Basin. 
and then results in evaporation from soil, vegetation, and part of streamflow. Therefore, the changes in precipitation and evaporation caused by increased temperature might be major drivers of changes of streamflow in the Yellow River Basin.

The largest increase changes in streamflow are observed at Tuotuohe Station (streamflow increased by $0.67 \mathrm{~mm} / \mathrm{a}$ ) in the head region and Zhimenda Station (streamflow increased by $0.46 \mathrm{~mm} / \mathrm{a}$ ) in the upstream reaches of the Yangtze River, and Xiangda Station (streamflow increased by $0.58 \mathrm{~mm} / \mathrm{a}$ ) in the head region of the Lantsang River Basin. Tuotuohe is the first gauge station in the Yangtze River Basin, at an altitude of more than $4,700 \mathrm{~m}$, which is the highest altitude gauge station in the study area. Annual precipitation and temperature in Tuotuohe increased during 1956-2013 (Fig. 8). The positive correlation between streamflow, precipitation, and annual temperature of Tuotuohe was found in this research. Glaciers became shorter, narrower, and thinner in the head region of the Yangtze River under the effect of atmospheric warming [7, 31]. Considering links between altitude, glacier melt, precipitation, and temperature [32], the changes in precipitation, glacier melt, and snowmelt might, therefore, be major drivers of change in streamflow in the mountainous headwater catchments of the Yangtze and Lantsang river basins, as well in Qaidam and Qinghai Lake basins. The conclusions in our study agree with previous studies [33-34], which indicated that such shifts in snowmelt timing or glacier melt due to increasing temperatures have been observed for mountainous catchments in western China since the beginning of the 21st century [35]. The influence of temperature on streamflow cannot be ignored, and factors such as
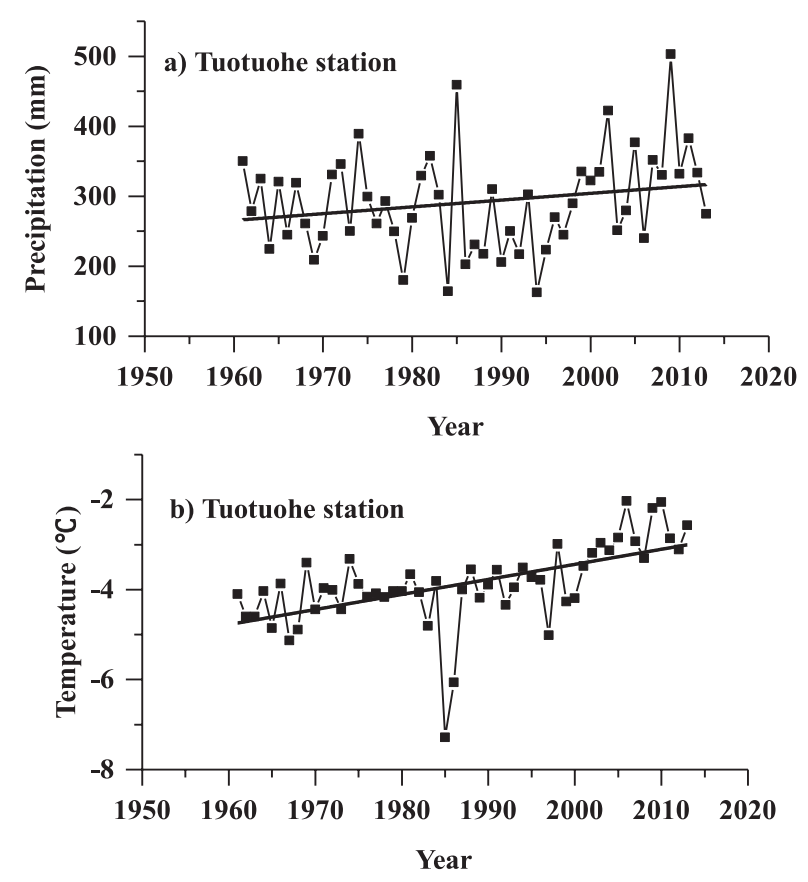

Fig. 8. Changes of streamflow, precipitation, and temperature at Tuotuohe Station in the Yangtze River Basin. glaciers, snow deposits, and frozen soil are closely related to temperature. The increasing temperatures may be a major driver of increasing streamflow in the mountainous headwater catchments. Due to the special geographical location of Qinghai Province, our future study should focus more on the effects of climate change on snow and glacier melting intensities as well as their contributions to streamflow hydrology.

\section{Abrupt Change}

Our results also found that most of the streamflow in Qinghai Province was abundant from circa 2007 to a certain year in the future, including the upper reaches of the Yellow River Basin as the source of the Yangtze, Yellow, and Lantsang rivers [36]. The result of MK test for abrupt change in Minhe showed that the intersection points of UF and UB curves appeared in 1964 and 1989 (Table 2 and Fig. 3). In reviewing prior reports and other relevant documentation [37], a large area of precipitation occurred in the flood season in 1989, which may cause an abrupt change in Minhe Station. Li [38] demonstrated that abrupt climate change is the direct cause of natural runoff, and abrupt change of the sunspot and the rotation period of the earth is the root cause of the change of runoff. The reasons for this phenomenon were not considered in the present study and need to be further investigated in the future.

\section{Periodicity}

In our study, the streamflow in Zhimenda and Tangnaihai stations (more than 100,000 km²) exhibits the dominant periods with low frequency fluctuation (about 12 years) and inter-decadal oscillations (about 44 years). Other stations (less than $20,000 \mathrm{~km}^{2}$ ) exhibit the dominant periods with low frequency fluctuation (about 5 years). In short, the area of the basin affects the low frequency fluctuation. No regulars were found with interdecadal oscillations when considering the control areas of the stations. This probably is due to the short period in our studies. Recent research also showed that the interannual variation of runoff is very distinct, and the domain periods include high-frequency fluctuation time domain and the lower [39]. It should be pointed out that the distinguishing periodicity of streamflow may be caused by special geomorphic features.

\section{Conclusions}

Based on the observation streamflow data of representative stations in Qinghai Province, temporal and spatial trends, abrupt change, and periodicity of streamflow has been analyzed. The main conclusions of this paper are:

1. The annual streamflow at the Yangtze River, Qaidam, Qinghai Lake, and Lantsang River basins shows a significantly increasing trend during 1956-2013, 
while it shows no significant trend or downward trend at the Yellow River Basin. This showed that there is a potential water resources crisis in the Yellow River Basin.

2. The trend variations of flow in the Yellow River Basin may have been affected by precipitation and evaporation caused by increased temperature and anthropogenic impacts, such as building reservoirs, water consumption for irrigation, and increasing forest cover, etc. The changes in precipitation, glacier melt, and snowmelt might, therefore, be a major driver of changes of streamflow in the mountainous headwater catchments of the Yangtze River and Lantsang River basins.

3. The abrupt changes of streamflow in Qinghai Province were studied. The abrupt changes of streamflow at Tuotuohe, Delingha, and Nachitai stations were mainly in the early 2000s, while the abrupt changes of streamflow in Zhimenda Station, and stations in Yellow River, Qinghai Lake, and Lantsang River basins appeared primarily in the early 1960s and the early 2000 s.

4. Wavelet transform shows that most of the streamflow in Qinghai Province was abundant from circa 2007 to a certain year in the future. In addition, there are exhibited the dominant periods with low frequency fluctuation (about 12 years) and inter-decadal (about 44 years) oscillations in Zhimenda and Tangnaihai stations, and low frequency fluctuation (about 5 years) in other stations.

\section{Acknowledgements}

This work was supported by the Key Projects of National key Research and Development Plan (2017YFC0504604), the National Science-technology Support Plan Projects (2015BAD07B030302) and the Qinghai Province Natural Science Foundation Project (2015-ZJ-902).Thanks also to the editors and one anonymous reviewer for their constructive comments on the earlier draft, which led to a great improvement of the final paper.

\section{References}

1. SILBERSTEIN R.P., ARYAR S.K., DURRANT J., PEARCEY M., BRACCIA M., CHARLES S.P., BONIECKA L., HODGSON G.A., BARI M.A., VINEY N.R., MCFARLANE D.J. Climate change and runoff in south-western Australia. J. Hydrol. 475, 441, 2012.

2. JIANG J.P., SHARMA A., SIVAKUMAR B., WANG P. A global assessment of climate-water quality relationships in large rivers: an elasticity perspective. Sci. Total environ. 468-469, 877, 2014.

3. TANG C.C., ZHONG L.S., KRISTEN M., CHENG S.K. A comprehensive evaluation of tourism climate suitability in Qinghai Province, China. J. Mt. Sci-Engl. 9 (3), 403, 2012.
4. WAN W., XIAO P.F., FENG X.Z., LI H., MA R.H., DUAN H.T., ZHAO L.M. Monitoring lake changes of QinghaiTibetan Plateau over the past 30 years using satellite remote sensing data. Chin. Sci. Bull. 59 (10), 1021, 2014.

5. SEN A.K., NIEDZIELSKI T. Statistical Characteristics of Riverflow Variability in the Odra River Basin, Southwestern Poland. Pol J Environ Stud. 19 (2), 387, 2010.

6. BIAN H.Q., LU H.S., SADEGHI A.M., ZHU Y.H., YU Z.B., OUYANG F., SU J.B., CHEN R.S. Assessment on the Effect of Climate Change on Streamflow in the Source Region of the Yangtze River, China. Water-Sui. 9 (1), 2017.

7. WU S.S., YAO Z.J., HUANG H.Q., LIU Z.F., CHEN Y.S. Glacier retreat and its effect on stream flow in the source region of the Yangtze River. J. Geogr. Sci. 23 (5), 849, 2013.

8. QIAN K.Z., WAN L., WANG X.S., LV J.J., LIANG S.H. Periodical characteristics of baseflow in the source region of the Yangtze River. J. Arid Land. 4 (2), 113. 2012.

9. ZHANG Y.Y., ZHANG S.F., ZHAI X..Y., XIA J. Runoff variation and its response to climate change in the Three Rivers Source Region. J. Geogr. Sci. 22 (5), 781, 2012.

10. HU Y.R., MASKEY S., UHLENBROOK S., ZHAO H.L. Streamflow trends and climate linkages in the source region of the Yellow River, China. Hydrol. Process. 25 (22), 3399, 2011.

11. BAI P., LIU W.H, GUO M.J. Impacts of climate variability and human activities on decrease in streamflow in the Qinhe River, China. Theor. Appl. Climatol. 117 (1-2), 293, 2014.

12. AMO-BOATENG M., LI Z.J., GUAN Y.Q. Inter-annual variation of streamflow, precipitation and evaporation in a small humid watershed (Chengcun Basin, China). Chin. J. Oceanol. Limn. 32 (2), 455, 2014.

13. OMAR O., CAMPOS M., SEVILLA N.P., GUEERRERO R., DIEGUEZI E., RUIZ P. Hydroclimatic Trends in Areas with High Agricultural Productivity in Northern Mexico. Pol J Environ Stud. 24 (3), 1165, 2015.

14. ZHANG W.C., XIAO Z.N., ZHENG J.M., REN J.Z. Characteristics of the Nujiang River runoff for a long term and its response to climate change. Chin. Sci. Bull. 52, 156, 2007.

15. XU J.H., CHEN Y.N., LI W.H., JI M.H., DONG S., HONG Y.L. Wavelet analysis and nonparametric test for climate change in Tarim River Basin of Xinjiang during 1959-2006. Chin. Geogr. Sci. 19 (4), 306, 2009.

16. HAN Z., SONG W., DENG X. Z. Responses of Ecosystem Service to Land Use Change in Qinghai Province. Energies. 9 (4), 2016.

17. FENG L.L., JIA Z.Q., LI Q.X., XU K. Fractional Vegetation Cover Estimation Based on MODIS Satellite Data from 2000 to 2013: a Case Study of Qinghai Province. J. Indian Soc. Remote. 44 (2), 269, 2016.

18. YUE S., PILON P., PHINNEY B., CAVADIAS G. The influence of autocorrelation on the ability to detect trend in hydrological series. Hydrol. Process. 16 (9), 1807, 2002.

19. LI E., MU X. M, ZHAO G.J, GAO P., SHAO H.B. Variation of runoff and precipitation in the Hekou-Longmen region of the Yellow River based on elasticity analysis. The Scientific World Journal. 2014.

20. HERMIDA L., SANCHEZ J.L., LOPEZ L., BERTHET C., DESSENS J., GARCIA-ORTEGA E., MERINO A. Climatic trends in hail precipitation in France: spatial, altitudinal, and temporal variability. The Scientific World Journal. 2013.

21. SHI W., XIA J., ZHANG X. Influences of anthropogenic activities and topography on water quality in the highly regulated Huai River basin, China. Environ. Sci. pollut. Res. Int. 23, (21), 21460. 2016. 
22. CHAUDHURI S., DUTTA D. Mann-Kendall trend of pollutants, temperature and humidity over an urban station of India with forecast verification using different ARIMA models. Environ. Monit. Assess. 186 (8), 4719, 2014.

23. ZHAO W., YU X., MA H., ZHU Q., ZHANG Y., QIN W., AI N., WANG Y. Analysis of Precipitation Characteristics during 1957-2012 in the Semi-Arid Loess Plateau, China. PloS one. 10 (11), 2015.

24. MOHAMMADI G., M., EBRAHIMI K. Effects of human activities and climate variability on water resources in the Saveh plain, Iran. Environ. Monit Assess. 187 (2), 35, 2015.

25. ZHAO B., XU J., CHEN Z, BAI L., LI P. Air temperature change in the southern Tarim River Basin, China, 19642011. The Scientific World Journal. 2013.

26. MIAO C.Y., NI J.R. Variation of natural streamflow since 1470 in the middle Yellow River, China. Int. J. Environ. Res. Public health. 6 (11), 2849, 2009.

27. HE B., MIAO C., SHI W. Trend, abrupt change, and periodicity of streamflow in the mainstream of Yellow River. Environmental monitoring and assessment. 185 (7), 6187, 2013.

28. LI N., WANG L.C., ZENG C.F., WANG D., LIU D.F., WU X.T. Variations of Runoff and Sediment Load in the Middle and Lower Reaches of the Yangtze River, China (19502013). PloS one. 11 (8), 2016.

29. ZHOU L., LYU A.F. Investigating natural drivers of vegetation coverage variation using MODIS imagery in Qinghai, China. J Arid Land. 8 (1), 109, 2016.

30. WANG X.Y., BI H.X., SONG Q.F., LU S. W. Influence of Forest Coverage on Basin Runoff in China's Loess Plateau. Pol J Environ Stud. 24 (2), 743, 2015.
31. YAO Z.J., LIU Z.F., HUANG H.Q., LIU G.H., WU S.S. Statistical estimation of the impacts of glaciers and climate change on river runoff in the headwaters of the Yangtze River. Quatern Int. 336, 89, 2014.

32. LUTZ S.R., MALLUCCI S., DIAMANTINI E., MAJONE B., BELLIN A., MERZ R. Hydroclimatic and water quality trends across three Mediterranean river basins. Sci. Total environ. 571, 1392, 2016.

33. WANG H., YU X. Sensitivity analysis of climate on streamflow in north China. Theor Appl Climatol. 119 (1-2), 391, 2014.

34. BRIKOWSKI T.H. Applying multi-parameter runoff elasticity to assess water availability in a changing climate: an example from Texas, USA. Hydrol. Process. 29 (7), 1746, 2015.

35. YI X.S., LI G.S., YIN Y.Y. Temperature variation and abrupt change analysis in the Three-River Headwaters Region during 1961-2010. J Geogr Sci. 22 (3), 451, 2012.

36. YI X.S., LI G.S., YIN Y.Y. Spatio-temporal variation of precipitation in the Three-River Headwater Region from 1961 to 2010. J Geogr Sci. 23 (3), 447, 2013.

37. LIU S.Y., HHANG Q. Abrupt change and variation characteristics of runof in the upper reachers of Datong River basin. Journal Of Northwest A \& F University. 44 (3), 219, 2016.

38. LI C.H., ZHENG X.K., PENG A.P. Analysis on Runoff Mutation of 1919-1998 Period of the Yellow River Basin. Yellow River. 30 (6), 33, 2008.

39. XU J.H., CHEN Y.N., LI W.H., JI M.H., DONG S., HONG Y.L. Wavelet analysis and nonparametric test for climate change in Tarim River Basin of Xinjiang during 1959-2006. Chin. Geogr. Sci. 19 (4), 306, 2009. 